\title{
Delivering psychiatric care to prisoners: problems and solutions
}

\author{
John Reed
}

'In some few jails are confined idiots and lunatics, many of the bridewells are crowded and offensive, because the rooms which were designed for prisoners are occupied by lunatics. The insane, when they are not kept separate, disturb and terrify other prisoners. No care is taken of them, although it is probable that by medicines, and proper regimen, some of them might be restored to their senses, and usefulness in life' (Howard, 1784: pp. 10-11).

'I have always found it strange that a patient [in prison] suffering from a medical emergency can be in the nearby general hospital within 30 minutes but if they are floridly psychotic it takes 30 days at least to find an appropriate disposal' (senior medical officer in a large local prison, May 2000).

On 14 December 2001 there were 68088 people detained in prison in England and Wales. The prison population has risen steeply in recent years and is projected to rise even further, reaching more than 92000 by 2005 (White \& Powar, 1998) (Fig 1). Mental health problems are common among prisoners and about 5000 have a psychotic illness (Singleton et al, 1998). Many would be much more appropriately cared for in the National Health Service (NHS) (Coid 1988; Brooke et al, 1996). Psychiatrists can help to prevent people with mental disorders from being detained inappropriately in prison and improve their mental health care while they are in prison. The purpose of this paper is to help psychiatrists to overcome some of the problems that they often encounter when visiting prisons.

Prisons exist for deterrence (deterring both prisoners and other citizens from crime), retribution (punishment for breaking society's laws), incapacitation (preventing the offender while in prison from committing further offences outside the prison walls) and reformation (fitting a prisoner to lead a law-abiding life on release) (Morris \& Rothman, 1995) (see Box 1). Punishment should be through deprivation of liberty, not through being treated worse than those who are not prisoners, and health care should be equivalent to that in the NHS.

\section{What sorts of prisoners and prisons are there?}

All prisoners are categorised on the basis of a risk assessment as being in one of four security categories

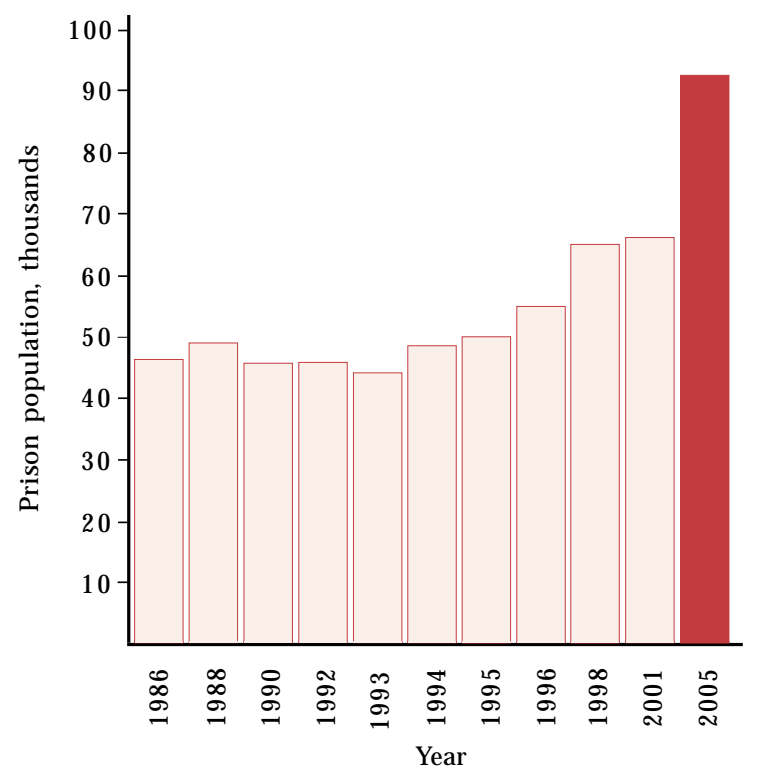

Fig. 1 Prison population, 1986-2001, projected

John Reed (HM Inspectorate of Prisons, Home Office, 50 Queen Anne's Gate, London SW1H 9AT, UK) worked as a psychiatrist before joining the Department of Health. He chaired the Department of Health/Home Office Review of Services for Mentally Disordered Offenders, High Security Psychiatric Care and of Psychopathic Disorder. Since September 1996 he has been the Chief Medical Inspector in Her Majesty's Inspectorate of Prisons. 


\section{Box 1 Why do prisons exist?}

Prisons exist for:

- deterrence (deterring both prisoners and other citizens from crime)

- retribution (punishment for breaking society's laws)

- incapacitation (preventing the offender while in prison from committing further offences outside the prison walls)

- reformation (fitting a prisoner to lead a lawabiding life on release)

(Box 2). There are 138 prisons in England and Wales. The great majority are state run, but nine are run on contract by the private sector and this number will increase. Prisons are categorised both by function and by the level of security they provide. The 45 local prisons hold both remand and sentenced prisoners and act as the entry point into the prison system. The five high-security (dispersal) prisons hold the most difficult long-term prisoners who pose a serious security risk; others take less risky category $\mathrm{B}$ and $\mathrm{C}$ prisoners, and the 10 'open prisons' hold prisoners posing minimal risks. There are also 13 women's prisons (and four wings for women in male prisons) and young offender institutions for juveniles and those aged 18-21. However, many prisons have mixed functions; local prisons may contain category A prisoners or even exceptional risk prisoners. Many short-sentence prisoners remain in local prisons throughout their sentences.

Box 2 The categories of prisoners in England and Wales

Category A Prisoners whose escape would be highly dangerous to the public, to the police or to national security; the most dangerous may be categorised as 'exceptional risk' prisoners

Category $B$ Prisoners not requiring the highest conditions of security but for whom escape must be made very difficult

Category C Prisoners who cannot be trusted in open conditions but who do not have the will or resources to make a determined escape attempt

Category D Prisoners who can be trusted to serve their sentence in open conditions

\section{Medical services in prisons}

Prisons differ in the extent and quality of their health care service. Some, mostly category $C$ training prisons and open prisons, with longer-term populations often have a primary care service with a local general practitioner (GP) providing a service not that different to the NHS and supported by visiting specialists such as psychiatrists. Others, particularly the local prisons taking prisoners, perhaps up to 100 a day, directly from courts and often off the streets, have a much more complex task. Their health care service often includes in-patient beds in the health care centre, and medical staff are much more likely to be directly and solely employed by the prison service. It is the health care services in local prisons that cause HM Inspectorate of Prisons most concern. One prison (Grendon Underwood) acts as a therapeutic community mainly for prisoners whose offending is related to personality disorders of moderate severity.

\section{What are the policy objectives for prison health care?}

Present policy objectives are that prisoners, whether sentenced or unsentenced, should 'have access to the same quality and range of health services as the general public receives from the NHS' (NHS Executive \& HM Prison Service, 1999) and that 'mentally disordered offenders needing care and treatment should receive it from health and personal social services rather than in custodial care' (Department of Health \& Home Office, 1992). But the quality of health care in prisons has long been found far worse than that which generally applies in the NHS (HM Inspectorate of Prisons, 1996) and since 1999 an objective has been to develop a new partnership between prisons and the NHS (NHS Executive \& HM Prison Service, 1999) with prisons and their local health authorities assessing the health care needs of the prison's population and including these in the health authority's health improvement programme.

\section{Psychiatric morbidity among prisoners}

A recent study by the Office for National Statistics (ONS) (Singleton et al, 1998) showed that 9 out of 10 
prisoners showed evidence of one or more mental disorder. Ten per cent of men on remand and $14 \%$ of all female prisoners had shown signs of psychotic illness in the year prior to interview in prison compared with $0.4 \%$ in the general household population (Meltzer et al, 1994). Fifty-nine per cent of remanded men and $76 \%$ of remanded women had a neurotic disorder. Over a quarter of female remand prisoners reported attempting suicide in the preceding year and $2 \%$ of both male and female remand prisoners reported attempting suicide in the week before interview. Fifty-eight per cent of male and 36\% of female remand prisoners met the criteria for previous hazardous drinking and $66 \%$ of remanded women had misused drugs in the year prior to entry into prison. Comorbidity was the norm; 7 out of 10 prisoners had more than one disorder, and those with functional psychosis were likely to have three or four other disorders including drug and alcohol misuse. There is limited evidence to suggest that elderly prisoners may be particularly likely to suffer from mental health problems (Box 3). A study in a remand prison in England that included 23 prisoners over the age of 65 found that $55 \%$ had active symptoms of psychiatric illness (Taylor \& Parrott, 1988).

\section{Why are there so many people with mental illness in prison?}

It is popularly believed that the presence of large numbers of mentally disordered offenders (MDOs) in prison is due to the running down and closure of the large old psychiatric hospitals, but in the absence of 'before and after' prevalence studies and other research this hypothesis cannot be tested. Certainly, the presence of people with mental illness in prison is not a new phenomenon. Over 200 years ago John Howard (Howard, 1784) noted that the presence of 'idiots and lunatics' in prison was bad not only for the MDOs themselves but was also distressing for the general run of prisoners. A century ago, at the height of the asylum system, Thomas Holmes (1900) described 'the ever increasing army of the demented' coming before magistrates' courts, criticised the remanding of defendants to prison for medical reports and was concerned at the lack of training of prison doctors.

Changes in society and in the scale and nature of offending make it unlikely that there is any simple explanation for the presence of so many people with mental illness in prison. Research has shown a number of factors that make it more likely that those with mental disorder, particularly mental illness, will be remanded to prison. People with mental disorder are more likely than those without mental disorder in similar circumstances to be arrested (Teplin, 1984). Not only are people with mental illness who commit acts of violence perceived as more dangerous simply by virtue of their mental illness, but remand is also more likely, even when lesser offending occurs in association with mental illness (Taylor \& Gunn, 1984). Other factors relating to an individual's immediate circumstances and which may be consequent on mental illness, such as homelessness, also make remand more likely (Michaels et al, 1992). Once a person with mental illness has come into contact with the criminal justice system the shortage of acute general psychiatric beds and the very slow development of the secure psychiatric bed programme (Department of Health \& Home Office, 1993) and its continuing inadequacy (James, 1999) makes it very difficult to move many patients to more appropriate placements.

\section{Roles for psychiatrists}

From the perspective of those working in prisons there are three important things for psychiatrists and the wider NHS mental health service to do to

\section{Box 3 Mental health among prisoners}

Prisoners, both remand and sentenced, have very high levels of psychiatric morbidity compared with the general population

Nine out of ten prisoners show evidence of one or more mental disorder

Ten per cent of men on remand and $14 \%$ of all female prisoners had shown signs of psychotic illness in the year prior to interview in prison (compared with $0.4 \%$ in the general household population)

Over a quarter of female remand prisoners reported attempting suicide in the preceding year and $2 \%$ of both male and female remand prisoners reported having attempted suicide in the week before interview

Fifty-eight per cent of male and $36 \%$ of female remand prisoners met the criteria for previous hazardous drinking and $66 \%$ of remanded women had misused drugs in the year prior to entry into prison 
improve mental health care for offenders or those at risk of offending:

- ensure that patients with serious mental illness do not enter the criminal justice system by effective follow-up and through diversion schemes

- return them to NHS care as rapidly as possible if they do enter the criminal justice system and meet the criteria for transfer under the Mental Health Act 1983

- advise on their treatment in prison if they do not meet the criteria for transfer.

\section{Effective follow-up of patients} and the reduction of offending

The ONS study (Singleton et al, 1998) showed that the very great majority of people with mental illness in prison, particularly those with the most serious disorders, had been in contact with the NHS and other services before they entered prison. Sixty-five per cent of male and $79 \%$ of female remand prisoners with psychosis had been in touch with mental health services before coming into prison. There is great scope, through better application of the Care Programme Approach and risk assessment, for preventing those with serious mental illness falling out from care and entering prison (Shaw et al, 2001). This needs to be coupled with a clear agreement about the roles and responsibilities of local general psychiatric and regional forensic psychiatric services in relation to patients involved with the criminal justice system.

\section{Diversion from the criminal justice system}

If a person with mental disorder from your catchment area comes into contact with the criminal justice system, you should have a central role in assessing and, whenever appropriate, diverting him or her back to the NHS.

\section{At the police station}

An alleged offender's first contact with the criminal justice system will be with the police. Studies of populations in custody in London police stations show high rates of mental disorder. Keyes et al (1995) suggested that $1.9 \%$ of those passing through one central London station presented with overt symptoms of mental illness. A report to the Home Office (Robertson et al, 1995) shows that $2.7 \%$ of those admitted to custody suites in London had some form of mental illness and $1.4 \%$ demonstrated symptoms of a serious nature. Similar and higher levels have been found outside London, with serious psychiatric disorder in $6.6 \%$ of 1460 held in custody overnight (Shaw et al, 1999). But schemes to assess and, if appropriate, divert patients with mental disorder at the level of first contact with the criminal justice system are not always effective (James, 2000) and not all custody suites are covered.

All services should operate effective assessment and diversion schemes at all police stations in their area.

At court

If diversion at the police station fails or is found inappropriate, the next opportunity, if prosecution follows, is at the magistrate's court. A recent review (National Schizophrenia Fellowship, 1999) showed that there were 118 schemes covering courts, although other reviews (Home Office, 1997) have suggested there are up to 150 court schemes. But there are 90 crown courts and some 340 magistrates' courts and the great majority of diversion schemes operate on a part-time basis only.

Research by HM Inspectorate of Prisons showed that of the 47 prisons taking unsentenced prisoners, only $17 \%$ had court diversion schemes operating in all the courts they served. Only $21 \%$ of prisons covered areas where $75 \%$ or more of courts had diversion schemes and $15 \%$ of prisons had less than $20 \%$ coverage. Worst served were three prisons where only $8 \%$ of courts operated diversion schemes. (HM Inspectorate of Prisons, 2000). Consequently, many people with mental disorder come into prison without full assessment and, if appropriate, diversion to health and social care. The effectiveness of diversion schemes is frequently limited by lack of suitable places to which to divert MDOs (James et al, 1998; James, 1999, 2000). Court assessment and diversion schemes covering all sessions of all courts should operate in all areas.

In prison

Once a patient with serious mental illness enters prison it becomes much more difficult to arrange transfer to more appropriate care. First, there is a problem with detecting illness. Many prisoners with serious mental health problems are not detected during the process of reception into prison. Of those compulsorily admitted to hospital through a court assessment scheme after a period of remand, 39\% had not been recognised as ill at the remand prison (Hudson et al, 1995). A study comparing screening by research workers and routine prison reception screening (Birmingham et al, 1998) found that routine screening failed to detect any indication of mental health problems in three-quarters of the remand prisoners identified by research workers. Even 
prisoners with psychotic disorders were no more likely to be identified than those with less serious conditions. Since the detection rate for serious mental illness at reception is so low, many seriously ill patients are placed in the general wings of a prison - on normal location - where even those who have psychoses are liable to remain undetected and untreated. There is some evidence that, although negative on health screening, discipline staff do recognise the abnormal behaviour of such prisoners (Birmingham, 1999) but believe that nothing can be done beyond containment (Hargreaves, 1997).

Even when mental illness is identified in prison there is cause for concern. The Inspectorate has found that in many prisons health care is of low quality, some doctors were not adequately trained to do the work they face and some care fails to meet proper ethical standards (Box 4). Prison health care standards were often not met or were simply ignored (Reed \& Lyne, 1997). The care of prisoners admitted as in-patients to prison health care centres is a matter of particular concern. In a survey of 13 in-patient units the Inspectorate found that no doctor in charge of in-patients with mental illness had completed specialist psychiatric training, only a quarter of nurses were trained in mental health and 32\% were nonnurse trained health care officers. Patients had a very restricted regime with very limited opportunities for any therapy except medication (Reed \& Lyne, 2000). Input from clinical psychologists and from occupational therapists to mental health care in prisons was very rare.

Psychiatrists working in prisons can play an important part not only in ensuring that these people with serious mental illness get appropriate treatment in an appropriate setting but also in educating all prison staff (not just health care staff) in the identification and management of mental disorder in prisoners. The Inspectorate has estimated that, if placement were determined by clinical need, a third of prison in-patients (some 500 patients) would be transferred to NHS psychiatric care, mainly to medium secure care. Nearly all prisons have psychiatrists who attend on a sessional basis; one or two have psychiatrists working either part-time or full-time. Most of these arrangements are longstanding and have been arranged between the prison and individual psychiatrists, sometimes without consideration as to whether the psychiatrist in question is suitably qualified and experienced. Prison governors tend to consider any doctor with some psychiatric experience and perhaps with a DPM as a fully trained psychiatrist. The Inspectorate has found prisons where the only psychiatric input is from non-consultant grade psycho-geriatricians or learning disability psychiatrists - backgrounds that seem to us to be unlikely to give the experience to deal with

\section{Box 4 Health care in prisons}

Health care services in prisons are rarely up to NHS standards

Primary care is often given by doctors who are not trained GPs

Primary care teams are virtually non-existent

Most prison in-patients have mental health problems but are usually not under the dayto-day care of psychiatrists, and multidisciplinary teams are non-existent

Many patients with psychosis requiring inpatient treatment wait for months for transfer to the NHS because of shortage of secure beds

the very disturbed patients often found in prisons. Most sessional psychiatrists working in prisons work single-handedly as private practitioners and any element of supervision is very rare indeed. Psychiatrists should help to define the appropriate level of experience, training and supervision needed by psychiatrists working in prisons. Contracts with trusts rather than individual doctors should be encouraged.

\section{Frequent problems and suggested solutions}

Psychiatrists often tell me about organisational problems that hamper their work in prisons. Prison staff (and patients) often tell me about the problems they have with the psychiatrists who visit them. Basic tips when visiting prisons include:

- book your visit and confirm it the day before

- take identification with you

- respect the prison's need to maintain security

- hand in mobile phones, pagers and dictation machines at the main gate

- do not forget to collect them when you leave

- do not resent being searched - it's no worse that at an airport.

Below are my suggestions for how to solve some problems you and the prison may encounter (see Box 5).

\section{What to expect from the prison}

Why do I find that I arrive at a prison to find that my patient has moved and nobody has told me?

Moves within the prison system often happen suddenly. Always ring the day before you are due to 


\section{Box 5 Seeing a patient in prison}

Telephone the day before the booked appointment to check that the patient is still there and will be available for interview

Accept that security checks are essential before you can enter the prison

Do not accept excuses if the patient is not available

Do not accept the non-availability of the inmate's medical record

Do not tolerate sexist or racist behaviour or talk

If you meet problems, insist on seeing the senior medical officer or the health care manager; if they cannot help, see the duty governor; if she or he also cannot help, see the governing (Number 1) governor

Transfer your patient to the NHS quickly for the sake of his or her health and safety

go to the prison and check that you are expected, that the patient has not been transferred elsewhere and that the notes will be available. Check also that the prisoner does not have a legal or domestic visit booked. The prisoner will chose these in preference to seeing you!

Why do I have to travel to a prison hundreds of miles from where I work and where the patient lives, turning a couple of hours consultation into a day's work?

Some prisons will now arrange for patients to be transferred temporarily to a prison near to your service to speed assessment. Check if this is possible. However, you will lose input from staff who have known the patient for longer.

When I arrive at the prison I'm told that all staff are involved in a training day and I can't be admitted.

When you book your time to see a patient get an assurance that the prison will be operating normally then and record the name of the person from whom you got this assurance. Check this the day before you go. If there is still a problem, ask to see the duty governor.

I'm kept waiting at the prison gate for ages while my escort arrives.

If you attend the prison regularly it may be worth your while to ask to undergo key training to allow the prison to issue you with your own set of keys. This will enable you to go unescorted to the health care centre. Some psychiatrists fear that having keys will result in prisoners identifying them with prison staff; in my experience this does not happen.

When I get to the health care centre I'm told the patient can't be unlocked because of staff shortages and would I mind interviewing the patient through the hatch

This is unacceptable except in the most extreme circumstances. Ask to see the senior medical officer and/or the health care manager. If this does not work, demand to see the governor.

I am subjected to sexist remarks and upset by the sexist attitudes and actions of prison staff

Sometimes psychiatrists are subjected to sexist remarks and sexist attitudes or actions by prison staff of either gender. The extent of the problem can vary from being stared at inappropriately, through sexual innuendo, comments and jokes to experiencing an over enthusiastic 'rub down' search. Prevention is the key to dealing with this common problem. It is essential to retain professional boundaries at all times; this includes behaving and dressing in a professional manner. Some psychiatrists chose to ignore relatively inoffensive sexist remarks or comments, at least in the first instance. Failure to respond tends to minimise any gain for the person who made the remark. If sexist remarks or behaviour cause offence, a quiet word with the individual concerned is often enough to prevent any repetition and gives the person concerned an opportunity to apologise. More serious harassment should always be reported to a senior member of the prison staff and a letter giving details of the complaint should be sent to the governor so that it can be dealt with directly by the Prison Service. Educational supervisors should facilitate discussion about possible sexual harassment during supervision sessions and give practical advice whenever necessary.

Similarly, psychiatrists may encounter an antipsychiatry attitude from some staff who think that psychiatrists tend to absolve offenders from their just punishment. Deal with this as with sexist remarks and actions (see Box 5).

\section{What the prison and the patient expect from you and the NHS}

From the patient's and the prison's perspective, the problem is to get a rapid assessment and, if appropriate, rapid transfer to NHS care or, if transfer is not appropriate, to get specialist advice on 
management in prison. Prisons and patients with mental illness in prisons encounter problems in the following areas.

\section{Deciding which service/consultant is responsible}

Uncertainty on area of residence/area of offending rules causes endless problems and delays. Even when the responsible service is clear, identifying the appropriate consultant can be difficult. Patients and prisons expect that you and your consultant colleagues will have worked out how to respond to requests from prisons.

\section{Waiting a long time for a psychiatrist to visit}

Patients often wait weeks or even months before a psychiatrist arrives to do a first assessment. Patients and prisons expect that MDOs wait for an initial assessment no longer than clinically comparable patients in the community.

\section{Disputes within the NHS psychiatric service}

After assessment and agreement that transfer to the NHS is appropriate, a common problem is that differences of opinion arise about the level of security a patient needs. It is common for patients to wait in prison while they are passed back and forth from local service to medium secure service to special hospitals and back again. I have found prisoners with serious mental illness waiting in prison where treatment is entirely inadequate for over a year while this debate goes on. Patients and prisons expect that there is a method of speedily resolving these disputes.

\section{Delays in transfer once accepted}

Even when accepted for transfer, patients can wait for months in prison, again largely untreated, until a suitable bed is available. The longest wait I have found from acceptance to transfer was 20 months pending admission to Broadmoor. A recent visit to a young offenders institution showed that at least 10 young people were awaiting transfer to the NHS and that the average waiting time was 82 days. I have found only one forensic mental health service able promptly to transfer out patients with serious mental illness from their local prison. Patients in prison tend to be given a low priority compared with others awaiting admission to the very stretched secure psychiatric service because once in prison they are considered to be in a place of safety and getting some treatment - in our view this is a misperception. Eighty-one prisoners committed suicide in 2000 and admission to the prison's health care centre does not protect from suicide - around a quarter of all suicides in prison take place in the health care centre (HM Inspectorate of Prisons, 1999). When seeing a patient in prison psychiatrists should enquire closely about the patient's day in prison and what therapy apart from medication is available. Very often they will find that their patient is locked in his or her room for 20 hours a day with no meaningful therapeutic activity. They should, in addition to interviewing their patient, also look at the conditions in which he or she lives while in prison. During a recent visit I found a prison health care centre with 10 in-patients awaiting transfer to the NHS. Several had no furnishing in their room besides a concrete plinth bed with an uncovered foam mattress and no blankets. This was not for clinical reasons but because the prison had not bothered to replace broken furniture.

Remember that prison health care centres are, quite rightly, not recognised as hospitals for the purposes of the Mental Health Act 1983 and so treatment cannot be given without consent except in emergencies under common law. Often, patients waiting in prison for transfer to the NHS have to be allowed to deteriorate until their condition is so severe that intervention under common law can be justified. Patients will expect you to take account of these legal restrictions and the very limited facilities for care in prison when you prioritise admissions.

\section{Writing reports}

Many reports by psychiatrists visiting patients in prison at the request of the prison health care service are excellent and provide a very valuable history, mental state assessment, differential diagnosis and suggested treatments. A significant minority, however, are of very much lower quality and often fail to provide the guidance that prison health care staff need to manage their patient. Some reports from visiting psychiatrists that I read are so bad that I, as a psychiatrist rather than as an inspector, find them an embarrassment. Some visiting 'psychiatrists' are in fact not psychiatrists, never having completed specialist training. Patients and prisons expect that visiting psychiatrists are fully trained (or are supervised by a trained psychiatrist), have kept their skills up to date through continuing professional development and have had specific training in writing reports.

In short, prison is a bad place for most people with serious mental illness. Their illness may not be detected and even if a serious mental health problem is uncovered, appropriate management and placement is far from certain. Delays in transfer to NHS hospitals, poor communication between prisons, courts and hospitals, and the rapidly changing remand population, means that patients often get 
inadequate treatment and can easily slip through the net and become lost to follow-up. If a person with mental illness has not been diverted to the NHS at a police station or court, then admission to prison should present an opportunity to assess the needs of patients often difficult to engage with psychiatric services and to ensure that they are met. This unique opportunity is rarely used effectively. Psychiatrists can help to improve this sorry situation.

\section{References}

Birmingham, L. (1999) Prison officers can recognise hidden psychiatric morbidity among prisoners. BMJ, 319, 853.

-, Mason, D. \& Grubin, D. (1998) A follow-up study of mentally disordered men remanded to prison. Criminal Behaviour and Mental Health, 8, 202-213.

Brooke, D., Taylor, C., Gunn, J., et al (1996) Point prevalence of mental disorder in unconvicted male prisoners in England and Wales. BMJ, 313, 1524-1527.

Coid, J. (1988) Mentally abnormal prisoners on remand: 1 Rejected or accepted by the NHS. BMJ, 296, 1779-1782.

Department of Health \& Home Office (1992) Review of Health and Social Services for Mentally Disordered Offenders and Others Requiring Similar Services. Final Summary Report. London: HMSO.

_ \& - (1993) Review of Health and Social Services for Mentally Disordered Offenders and Others Requiring Similar Services. Volume 2: Service Needs. London: HMSO.

Geelan, S., Griffin, N., Briscoe, J., et al (2000) A bail and probation hostel for mentally disordered defendants. Journal of Forensic Psychiatry, 11, 93-104.

Hargreaves, D. (1997) The transfer of severely mentally ill prisoners from HMP Wakefield: a descriptive study. Journal of Forensic Psychiatry, 8, 62-73.

HM Inspectorate of Prisons (1996) Patient or Prisoner? London: Home Office.

- (1999) Suicide is Everyone's Concern. London: Home Office.

- (2000) Unjust Deserts; Treatment and Conditions for Unsentenced Prisoners in England and Wales. London: Home Office.

Holmes, T. (1900) Pictures and Problems from London Police Courts. London: Nelson.

Home Office (1997) Mentally Disordered Offenders: Survey of Inter-Agency Arrangements. Circular MNP97 1/71/1. London: Home Office

Howard, J. (1784) The State of the Prisons in England and Wales (3rd edn). Warrington.

Hudson, D., James, D., Etherington, D., et al (1995) Psychiatric Intervention at the Police Station. London: Riverside Mental Health.

James, D. (1999) Court diversion at 10 years: can it work, does it work and has it a future? Journal of Forensic Psychiatry, 10, 507-524.

- (2000) Police station diversion schemes: role and efficacy in central London. Journal of Forensic Psychiatry, 11, 532-555.

- Cripps, J., Gilluley, P., et al (1998) A court-focused model of forensic psychiatry: abolishing remands to prison. Journal of Forensic Psychiatry, 8, 390-405.

Keyes, S., Scott, S. \& Truman, C. (1995) People with Mental Health Problems in Contact with the Criminal Justice System: Report of a Service-Mapping Project in Camden and Islington. London: Revolving Doors Agency.

Meltzer, H., Gill, B. \& Petticrew, M. (1994) The Prevalence of Psychiatric Morbidity among Adults Aged 16-64, Living in Private Households, in Great Britain. London: Office of Population Censuses and Surveys.

Michaels, D., Zoloth, S., Alcabes, P., et al (1992) Homelessness and indicators of mental illness among inmates of New York City's correctional system. Hospital and Community Psychiatry, 43, 150-155.
Morris, N. \& Rothman, D. J. (eds) (1995) The Oxford History of the Prison, pp. ix-xii. Oxford: Oxford University Press.

NHS Executive \& HM Prison Service (1999) The Future Organisation of Prison Health Care. London: Department of Health.

National Schizophrenia Fellowship (1999) The National Schizophrenia Fellowship National Diversion/Liaison Scheme Register September 1999-April 2000. London: NSF.

Reed, J. \& Lyne, M. (1997) The quality of health care in prison: results of a year's programme of semi-structured inspections. BMJ, 315, 1320-1424.

- \& - (2000) Inpatient care of mentally ill people in prison: results of a year's programme of semi-structured inspections. BMJ, 320, 1031-1034.

Robertson, G., Pearson, J. \& Gibb, R. (1995) Entry of Mentally Ill People into the Criminal Justice System. London: Home Office.

Shaw, J., Creed, F., Price, J., et al (1999) Prevalence and detection of serious psychiatric disorder in defendants attending court. Lancet, 353, 1053-1056.

- Tomenson, B., Creed, F., et al (2001) Loss of contact with psychiatric services in people diverted from the crimina justice system. Journal of Forensic Psychiatry, 12, 203-211.

Singleton, N., Meltzer, H. \& Gatward, R. (1998) Psychiatric Morbidity among Prisoners in England and Wales. London: HMSO.

Taylor, P. J. \& Parrott, J. M. (1988) Elderly offenders. A study of age-related factors among custodially remanded prisoners. British Journal of Psychiatry, 152, 340-346.

— \& Gunn, J. (1984) Violence and psychosis: 1 Risk of violence among psychotic men. BMJ, 288, 1945-1949.

Teplin, L. (1984) Criminalising mental disorder. American Psychologist, 39, 794-803.

White, P. \& Powar, I. (1998) Revised Projection of Long Term Trends in the Prison Population to 2005. Home Office Statistical Bulletin 2/98. London: Home Office.

\section{Multiple choice questions}

1. Which of the following statements are true?

a prisons exist for punishment

b life in prison should be degrading

c prison keeps offenders off the streets

d prisoners have forfeited their right to good health care

e the general health of prisoners is no worse than that of non-prisoners.

2. Surveys of the mental health of prisoners show that: a psychotic illnesses are up to 28 times more common than in the general population

b comorbidity is unusual

c most prisoners with mental illness are not known to NHS mental health services

d $2 \%$ of all remand prisoners reported attempting suicide in the previous week

e over half of male remand prisoners meet the criteria for previous hazardous drinking.

3. Prisoners with serious mental illness:

a are likely to be detected by screening on entering prison

b are located in the health care centre

c can receive non-emergency treatment against their wishes 
d can be identified by prison officers when they are not known to health care staff

e all require transfer to the NHS.

4. Schemes to assess and divert MDOs from courts to the NHS:

a operate in all criminal courts

b operate during all court sessions

c often find it hard to find suitable NHS beds

$\mathrm{d}$ are managed only by forensic psychiatrists

e fail to identify some seriously ill patients.

5. If I visit prison to assess a patient, I should:

a tolerate sexist behaviour

b check the patient's availability the day before I am due to visit c insist on taking my mobile phone into the prison

$\mathrm{d}$ ask to be 'key trained' if I visit regularly

e complain to the governor if I cannot see my patient.

MCQ answers

$\begin{array}{llllllllll}\text { 1 } & & \text { 2 } & & 3 & & 4 & & 5 & \\ \text { a } & \text { T } & \text { a } & \text { T } & \text { a } & \text { F } & \text { a } & \text { F } & \text { a } & \text { F } \\ \text { b } & \text { F } & \text { b } & \text { F } & \text { b } & \text { F } & \text { b } & \text { F } & \text { b } & \text { T } \\ \text { c } & \text { T } & \text { c } & \text { F } & \text { c } & \text { F } & \text { c } & \text { T } & \text { c } & \text { F } \\ \text { d } & \text { F } & \text { d } & \text { T } & \text { d } & \text { T } & \text { d } & \text { F } & \text { d } & \text { T } \\ \text { e } & \text { F } & \text { e } & \text { T } & \text { e } & \text { F } & \text { e } & \text { T } & \text { e } & \text { T }\end{array}$

\section{Commentary}

\section{Luke Birmingham}

Anyone who has provided psychiatric care to prisoners will know that delivering a decent standard of care is very difficult. In this issue John Reed examines some of the most frequently encountered problems faced by psychiatrists working in prisons and he suggests some practical solutions to overcome these difficulties (Reed, 2002). The problems associated with health care in prisons are complicated, but the reason why prisoners receive substandard health care is fairly simple: the prison service is not set up to deal with the complex needs of mentally disordered offenders (MDOs)and the National Health Service (NHS) has been reluctant to help out.

\section{The role of the prison service}

Prisons are not there to provide care for MDOs who have fallen through the net of NHS services: their purpose is to punish offenders, protect the public from crime, enforce court orders and stop people who are involved with the courts from running away. Physical methods of confinement, regimes and strict rules used to maintain prison security hamper the delivery of health care and create an environment that is detrimental to mental health.

The prison estate consists of an assortment of buildings, many of which are old and unsuitable for a modern prison service. This is particularly true of prison health care facilities. Twenty-four-hour staffed in-patient health care centres are located in larger, more secure prisons. They provide a cottage hospital service for a cluster of nearby prisons with less comprehensive facilities.

There are around 140 doctors employed by the Prison Service to work as prison medical officers. Very few have backgrounds or specialist training in mental health, and only a handful hold qualifications in psychiatry. These doctors and other Prison Service employees, including nurses, health care

Luke Birmingham is a senior lecturer at the University of Southampton and an honorary consultant in forensic psychiatry at Ravenswood House Medium Secure Unit (Knowle, Fareham, Hampshire PO17 5NA, UK). He has research interests in prison mental health care and acts as a guest medical inspector for Her Majesty's Prison Inspectorate. 